\title{
Urgensi Kebijakan Pemberdayaan Masyarakat Miskin yang Menjadi Pasien di Rumah Sakit Dr. Soetomo Kota Surabaya
}

Oleh:

Saputra Adiwijaya

\begin{abstract}
Abstrak
Pembangunan suatu bangsa mutlak memerlukan sinergi yang baik antara pemerintah sebagai pembuat kebijakan dan masyarakat sebagai penerima kebijakan. Masyarakat yang masuk dalam kategori masyarakat miskin yang menjadi pasien di rumah sakit Dr. Soetomo, harus tetap mendapatkan pelayanan yang baik dan memenuhi standar. Pada kondisi di lapangan penerapan kebijakankebijakan kesehatan bagi masyarakat miskin seringkali tidak memenuhi standar sehingga kemudian didalam masyarakat itu sendiri diperlukan pemberdayaan agar kemandirian mereka bisa menjadi bahan perbaikan bagi pembangunan suatu bangsa.
\end{abstract}

Keywords: Pembangunan, kebijakan kesehatan, masyarakat miskin, dan pemberdayaan.

\section{Latar Belakang}

Pembangunan merupakan salah satu upaya suatu negara untuk memakmurkan dan mensejahterakan rakyatnya. Negara memberikan berbagai macam kebijakan dan program untuk kebaikan rakyatnya, salah satu kebijakan pembangunan itu adalah kebijakan pembangunan manusia, hal ini dimaknai sebagai upaya pemerintah untuk mencari dan menemukan cara yang tepat dalam mengurus masyarakatnya agar siapa pun yang menjadi warga negara menjadi terpenuhi segala macam hak-haknya.

Salah satu cakupan pembangunan bagi suatu negara disamping pembangunan lainnya adalah adalah pembangunan manusia. Pembangunan manusia ini disusun oleh pakar-pakar yang kemudian menjadi indikator keberhasilan sutau negara dalam mengurus rakyatnya. Pembangunan manusia ini bisa difahami sebagai partisipasi masyarakat untuk ikut serta dalam proses pembangunan sehingga arah negara menjadi semakin jelas dan terarah. Maka dalam hal ini kualitas manusia yang adal dalam suatu negara menjadi tolak ukurnya.

Di Indonesia kemudian tugas utama negara mulai dari lingkup nasional, propinsi dan kabupaten adalah menyelenggarakan pembangunan, berhasil tidaknya tugas utama negara ini harus dapat diukur untuk dapat melihat sejauhmana penyelenggaraan pembangunan tersebut berdampak pada kesejahteraan manusia, salah satu indikator penting untuk menilai keberhasilan dalam penyelenggaraan pembangunan adalah HDI yaitu singkatan dari Human Development Index atau dalam bahasa Indonesia Indeks Pembangunan Manusia. Indeks ini terdiri dari : Indeks ekonomi (pendapatan riil per kapita), Indeks pendidikan (angka melek huruf dan lama sekolah) dan Indeks kesehatan (umur harapan hidup waktu lahir). Karena HDI ini sebagai Indikator berhasil tidaknya dalam penyelenggaraan pembangunan (nasional, propinsi ataupun kabupaten) 
maka HDI ini harus mengandung unsur-unsur intervensi bila dalam penyelenggaraan pembangunan indeks yang dihasilkan mempunyai nilai rendah. Kalau diperhatikan dari ketiga sub indeks yang membentuk HDI hanya sub Indeks Kesehatan yaitu umur harapan hidup waktu lahir yang sulit untuk membentuk unsur intervensinya, oleh Karenanya harus dijabarkan lebih lanjut dengan kata lain diperlukan rumusan program yang nyata.

Berikut ini tiga sub indeks HDI dan intervensinya dari pemerintah melalui berbagai macam kebijakan dan program kepada masyarakat, yaitu :

1. Ekonomi: pendapatan per kapita, intervensinya jelas: pertumbuhan ekonomi dan pemerataan melalui perluasan lapangan kerja.

2. Pendidikan: melek huruf dan lama sekolah, intervensinya jelas: wajib belajar 9 tahun akan meningkatkan indeks pendidikan.

3. Kesehatan: umur harapan hidup waktu lahir

Untuk bidang kesehatan ternyata setiap daerah masing-masing intervensinya berbeda-beda, hal ini berkaitan dengan banyak factor misalnya kemiskinan. Maka kemudian dari HDI (Human Development Index) ini disusun kembali indikator nya yang istilahnya adalah IPKM (Indeks Pembangunan Kesehatan Manusia), oleh para pakar di Kementerian Kesehatan Republik Indonesia disusun 24 indikator yaitu :

1. Prevalensi balita gizi buruk dan kurang bobot 5

2. Prevalensi balita sangat pendek dan pendek bobot 5

3. Prevalensi balita sangat kurus dan kurus bobot 5

4. Prevalensi balita gemuk bobot 4

5. Prevalensi diare bobot 4

6. Prevalensi pnemonia bobot 4

7. Prevalensi hipertensi bobot 4

8. Prevalensi gangguan mental bobot 3

9. Prevalensi asma bobot 3

10. Prevalensi penyakit gigi dan mulut bobot 3

11. Prevalensi Disabilitas bobot 3

12. Prevalensi Cedera bobot 3

13. Prevalensi Penyakit Sendi bobot 3

14. Prevalensi ISPA bobot 3

15. Proporsi perilaku cuci tangan bobot 4

16. Proporsi merokok tiap hari bobot 3

17. Akses air bersih bobot 5

18. Akses sanitasi bobot 5

19. Cakupan persalinan oleh nakes bobot 5

20. Cakupan pemeriksaan neonatal-1 bobot 5

21. Cakupan imunisasi lengkap bobot 5

22. Cakupan penimbangan balita bobot 5

23. Ratio Dokter/Puskesmas bobot 5

24. Ratio Bidan/desa bobot 5

Selain menentukan peringkat pembangunan kesehatan kab/kota, IPKM dapat menjadi acuan pemerintah daerah (Pemda) membuat program intervensi yang lebih tepat, bahan advokasi ke Pemda agar terpacu menaikkan peringkat 
kesehatannya, perumusan daerah bermasalah kesehatan berat/khusus (DBKBK), dasar penentuan alokasi dana bantuan kesehatan dari pusat ke daerah, dan membantu Kementerian Negara Pembangunan Daerah Tertinggal (KMPDT) dalam membangun kab/kota.

Pada sisi yang lain masih tingginya angka kemiskinan di Indonesia membuat pemerintah membuat kebijakan untuk menyelaraskan program kesehatan bagi masyarakatnya. Secara sederhana kemiskinan membuat penduduk menjadi rentan sakit, hal ini tentu akan berdampak kepada produktifitas mereka yang umumnya bekerja pada profesi yang tidak tetap, ditambah lagi dengan lingkungan yang buruk.

\section{Gambaran Kemiskinan Di Kota Surabaya}

Berdasarkan data BPS (Badan Pusat Statistik) Provinsi Jawa Timur didapat (2012) bahwa jumlah penduduk miskin berdasarkan Jumlah dan Persentase Penduduk Miskin, Garis Kemiskinan, Indeks Kedalaman Kemiskinan (P1), dan Indeks Keparahan Kemiskinan (P2) Menurut Kabupaten/Kota, tahun 2011 khusus untuk kota Surabaya berjumlah 183,3 ribu orang, data ini juga berisikan data jumlah penduduk miskin dari daerah-daerah lain yang ada di Jawa Timur (jatim.bps.go.id). Berbeda dengan data dari dari Badan Pemberdayaan Masyarakat (Bapemas) dan KB Surabaya tahun 2011 untuk jumlah keluarga miskin (gakin) di Surabaya mencapai 112.465 atau sekitar 449.860 jiwa.

Pada bagian lain dalam Buku Profil Pengendalian Kuantitas Penduduk Jawa Timur (2013), didapat bahwa keadaan kemiskinan berkaitan erat dengan tingkat pertumbuhan ekonomi, maka didapat data Laju Pertumbuhan Ekonomi Jawa Timur tahun 2012 sebesar 7,5\% melampaui pertumbuhan ekonomi nasional 6,7\%. Angka tersebut meningkat daripada tahun 2011 dimana pertumbuhan ekonomi Jawa Timur sebesar 7,22\% sedangkan nasional 6,5\%. Angka kemiskinan di Jawa Timur juga terus menurun. Ini artinya berbagai program penanggulangan kemiskinan di Jawa Timur memberikan hasil cukup signifikan. Pada 2005 terdapat 22,51\% penduduk miskin di Jawa Timur, kemudian menurun menjadi 19,89\% pada 2006. Persentase penduduk miskin menunjukkan kecenderungan terus menurun. Pada 2007, menjadi 18,89\%, dan pada 2008 kembali menurun menjadi 16,97\%. Akhirnya berdasarkan data dari BPS Pusat 2011, Penduduk miskin di Provinsi Jawa Timur tahun 2011 adalah sebesar 14,23\% terdapat di Perkotaan sebesar 9,87\% dan di Perdesaan sebesar 18,19\%. Sementara persentase penduduk miskin nasional adalah sebesar $12,49 \%$.

Di kota Surabaya sebaran warga miskin meliputi daerah kelurahan di tiga kecamatan, yaitu di Kecamatan Semampir tersebar di Kelurahan Ujung, Pegirian, Wonokusumo dan Sidotopo. Kemudian Kecamatan Tambaksari di Kelurahan Gading, serta Kecamatan Simokerto di Kelurahan Simokerto.

\section{Kebijakan-Kebijakan Kesehatan Bagi Masyarakat Miskin}

Pemerintah dalam memberikan bantuan bagi warga yang terhimpit kemiskinan bidang kesehatan berlanjut dengan pemberian program JAMKESMAS (Jaminan Kesehatan Masyarakat), JAMKESDA (Jaminan Kesehatan Daerah), dan SKTM (Surat Keterangan Tidak Mampu) atau ada juga 
istilahnya SPM (Surat Pernyataan Miskin) dan yang terbaru adalah BPJS (Badan Penyelenggara Jaminan Sosial) melalui JKN (Jaminan Kesehatan Nasional). Semua program ini berjalan untuk memberikan pelayan bagi warga miskin, namun dalam beberapa pelaksanaanya masih terdapat berbagai macam kekurangan misalnya pelayanan yang diberikan oleh pihak rumah sakit tidak menyeluruh ketika warga miskin berobat, masih terdapat kesenjangan pada prakteknya ketika pihak rumah sakit melayani pasien miskin, hingga sistem pengurusan yang seakan-akan masih berbelit-belit.

Kemudian pada situasi di lapangan pelayanan kesehatan bagi warga miskin masih dianggap jauh dari standar yang sudah ditetapkan, hal ini tidak lepas dari kebijakan terbaru program layanan kesehatan bagi masyarakat terlebih khusus bagi masyarakat dengan kategori miskin. Kebijakan layanan kesehatan ini mengacu pada sebuah lembaga dengan Badan Penyelenggara Jaminan Sosial (BPJS) yang merupakan bagian dari Jaminan Kesehatan Nasioanl (JKN), masyarakat harus mendaftarkan diri untuk menjadi anggota BPJS dengan ketentuan adanya iuran bulanan yang harus dibayar sesuai dengan kemapuan masing-masing. Hal ini bertujuan untuk mengkategorikan jenis layanan kelas yang akan diterima jika menjalani rawat inap di rumah sakit.

Namun pada kenyataannya beberapa kalangan masyarakat menilai bahwa program BPJS lebih buruk dari layanan kesehatan sebelumnya seperti Jamksemas, Jamkesda, SKTM, hal ini terlihat pada kondisi dilapangan yang memperlihatkan keadaan yang jauh dari harapan ideal bagi pelayanan kesehatan untuk masyarakat, misalnya prosedur yang berbelit-belit, pelayanan rumah sakit yang sekedarnya, ditolak rumah sakit dengan alasan yang tidak jelas, biaya layanan perawatan yang ternyata masih tinggi, dokter tidak tepat penanganannya, hingga hanya rumah sakit induk saja yang mengcover semua pasien rujukan dari rumah sakit lain.

Hal ini sesuai dengan pernyataan Direktur BPJS Watch Jatim Arief Supriyono dalam harian SURYA (Sabtu,17 Januari 2015) bahwa adanya kelemahan pada system dan prosedur, selain itu juga disebabkan oleh praktek nakal dokter, puskesmas, klinik, dan rumah sakit yang menjadi provider program BPJS. Kemudian pada bagian lain ada beberapa modus yang bisa digunakan untuk memainkan pasien BPJS yaitu :

1. Kamar penuh ; dengan alasan kamar penuh, pasien terpaksa menerima layanan kelas bawah.

2. Layanan intensif ; pasien (BPJS-mandiri) diminta naik kelas untuk mendapat layanan lebih intensif (tambah biaya).

3. Memainkan resep ; oknum dokter memberi resep yang tidak masuk daftar BPJS, shingga harus membeli.

4. Pemeriksaan laboratorium ; petugas meminta tambahan biaya dengan alasan tidak semua jenis pemeriksaan discover.

5. Mengusir/merujuk pasien ; pasien yang lebih dari lima hari diminta pulang, kalau masuk lagi harus daftar baru lagi. Atau pasien dirujuk ke RSUD Soetomo dengan alasan peralatan kurang lengkap.

Keadaan ini lah kemudian menimbulkan pro dan kontra baik dikalangan para ahli, pemerintah, dokter, hingga masyarakat terlebih lagi bagi masyarakat miskin. Ada beberapa kalangan yang ingin bahwa program ini ditunda dulu, 
namun ada pula yang ingin agar program ini dijalankan terus, terlepas dari semua yang pro dan kontra tetap saja masyarakat yang menderita, karena situasi di lapangan sangat jauh dari harapan yangideal.

\section{Data - Data Pasien di RSUD Dr. Soetomo Kota Surabaya}

Jika dilihat berdasarkan data yang peneliti dapatkan ternyata jumlah pasien yang menggunakan program Jamkesmas, Jamkesda, dan SKTM pada rumah sakit Dr.Soetomo Surabaya sangat banyak, berikut ini adalah data jumlah pasien yang dilayani oleh rumah sakit Dr. Soetomo Surabaya yang masuk dalam kategori pelayanan kesehatan keluarga miskin dari tahun 2010 - 2012.

Tabel 1

Jumlah Total Pasien Miskin

dalam Pelayanan Rawat Inap Tahun 2010 - 2012

\begin{tabular}{|l|l|l|l|}
\hline Jenis Layanan & Tahun 2010 & Tahun 2011 & Tahun 2012 \\
\hline Jamkesmas & 12.870 & 7.978 & 9.923 \\
\hline Jamkesda & 2.558 & 6.234 & 6.574 \\
\hline SKTM & 2.283 & 6.773 & 5.505 \\
\hline
\end{tabular}

Sumber : Data Diolah dari Rumah Sakit Dr.Soetomo, 2014

Dari tabel di atas terlihat bahwa pada tahun 2010 dalam jenis pelayanan Rawat Inap rumah sakit Dr.Soetomo Surabaya menangani jumlah pasien terbanyak adalah 12.870 orang dengan jenis layanan Jamkesmas, sedangkan pasien paling sedikit adalah 2.283 orang dengan jenis layanan SKTM. Sedangkan untuk tahun 2011 - 2012 kisaran pasien yang ditangani antara 5.000 - 9.000 orang.

Tabel 2

Jumlah Total Pasien Miskin dalam Pelayanan Rawat Jalan Tahun 2010 - 2012

\begin{tabular}{|l|l|l|l|}
\hline Jenis Layanan & Tahun 2010 & Tahun 2011 & Tahun 2012 \\
\hline Jamkesmas & 6.212 & 40.567 & 79.028 \\
\hline Jamkesda & 3.659 & 32.486 & 63.732 \\
\hline SKTM & 2.877 & 29.569 & 64.329 \\
\hline
\end{tabular}

Sumber : Data Diolah dari Rumah Sakit Dr.Soetomo, 2014

Dalam tabel 2 untuk jenis layanan Rawat Jalan pada tahun 2010 2012 terjadi peningkatan yang luar biasa untuk jenis layanan ini. Jika di tahun 2010 kisarannya hanya 2.000 hingga 6.000 orang maka untuk tahun 2011 - 2012 lonjakannya besar sekali, dimana pada tahun 2012 dengan jenis layanan Jamkesmas mencapai 79.028 orang.

Tabel 3

Jumlah Total Pasien Miskin

dalam Pelayanan Rawat Darurat Tahun 2010 - 2012

\begin{tabular}{|l|l|l|l|}
\hline Jenis Layanan & Tahun 2010 & Tahun 2011 & Tahun 2012 \\
\hline Jamkesmas & 13.135 & 10.623 & 10.714 \\
\hline Jamkesda & 1.203 & 2.375 & 3.393 \\
\hline SKTM & 2.539 & 7.403 & 5.333 \\
\hline
\end{tabular}

Sumber : Data Diolah dari Rumah Sakit Dr.Setomo, 2014 
Sementara untuk pelayanan Rawat Darurat pada tahun 2010 terbanyak dalam menangani pasien yaitu 13.135 orang, kemudian pada tahun-tahun berikutnya memang terjadi penurunan tapi tidak begitu drastis, masih dikisaran 10.1 an orang yang ditangani. Sementara untuk jenis layanan Jamkesda dan SKTM kisarannya antara 1000 an orang hingga 5.000 an orang.

Dari ketiga tabel di atas dapatlah digambarkan bahwa, program Jamkesmas menjadi andalan bagi warga miskin untuk berobat ke rumah sakit Dr.Soetomo Surabaya, dengan berbagai kategori layanan mulai dari Rawat Inap, Rawat Jalan, dan Rawat Darurat semuanya digunakan oleh warga kota Surabaya. Maka kemudian hal ini merupakan tantangan besar untuk memberikan pemberdayaan bagi masyarakat yang masuk dalam kategori pasien miskin.

Keadaan warga miskin yang menerima program Jamkesmas ini, pernah diteliti oleh Warsono,dkk (2011) penelitian ini berhasil memetakan permasalahan yang dihadapi pada program Jamkesmas di daerah Jawa Tengah dan Jawa Timur, yang hasilnya ada tiga aspek yang perlu dibenahi yaitu dari sisi substansi, mekanisme, dan kelembagaan. Penelitian ini memang benar menghasilkan identifikasi dan rekomendasi kepada pihak yang berwenang namun hanya membahas secara umum program Jamkesmas. Sementara analisis untuk mengetahui situasi dan kondisi pasien ataupun keluarga pasien yang masuk dalam kategori miskin yang menjalani rawat inap di rumah sakit Dr.Soetomo Surabaya belum ada, rekomendasi yang dihasilkan masih dalam tataran konsep umum.

Selain itu penelitian yang dilakukan oleh Muhith (2012), dalam penelitian ini fokusnya pada mutu pelayanan kesehatan oleh rumah sakit, dengan karakter mutu pelayanan prima yang sesuai dengan harapan pasien, yang berdasarkan pada penanaman kepercayaan dan kredibilitas. Dalam penelitian ini teori yang digunakan berpedoman pada kualitas pelayanan keperawatan sebagai salah satu kebutuhan dasar manusia, oleh sebab itu mutu pelayanan kesehatan bisa dimulai dari :

1. Struktur yang meliputi sarana fisik, peralatan, dana, tenaga, kesehatan, serta pasien.

2. Proses yang meliputi manajemen rumah sakit, manajemen interpersonal, maupun manajemen teknis serta mutu pelayanan rumah sakit, yang kesemuanya tecermin pada tindakan medis dan non medis kepada pasien.

3. Outcome yang meliputi hasil akhir dari kegiatan dan tindakan professional terhadap pasien (Donabedian,1980).

Ketiga hal itu masih harus diperkuat dari upaya lain yang dilakukan yaitu mutu diri, profesi, peralatan keperawatan, kemampuan manajerial keperawatan, dan mutu asuhan keperawatan (Potter and Perry, 2005).

Lalu dari hasil penelitian Muhith (2012) diperoleh bahwa penelitian ini menekankan pada pelayan kesehatan yang dilakukan oleh perawat kepada pasien, namun hanya sebatas memberikan respon melalui kuisioner atau dengan kata lain bahwa penelitian ini meneliti tugas perawat dalam pelayanannya kepada pasien sebagai tugas utamanya di rumah sakit, kemudian oleh peneliti dikembangkan model manajemen pelayanan yang akan dikembangkan terhadap rumah sakit. Sehingga penelitian ini belum merepresentasikan pemberdayaan warga atau 
masyarakat yang masuk dalam kategori pasien miskin yang menjalani rawat inap di rumah sakit.

\section{Tinjauan Sisi Pemberdayaan}

Perubahan paradigma pembangunan pada masa sekarang telah menjadikan masyarakat dituntut berperan serta dalam kemajuan suatu bangsa dan negara. Jika sebelumnya masyarakat hanya sebagai penikmat atau bahkan penonton saja dalam proses pembangunan maka pada masa sekarang masyarakat berhak mempunyai andil dalam proses pembangunan itu. Idealnya adalah tercipta hubungan yang harmonis antara masyarakat dengan pemerintah sehingga program pembangunan yang ditujukan ke masyarakat dapat tepat sasaran dan tidak sia-sia. Masyarakat perlu memberikan masukan, dan pemerintah berkewajiban memperhatikan segala macam masukan itu, namun pada prakteknya terkadang pemerintah mengabaikan segala macam masukan itu, sehingga pembangunan menjadi tidak tepat.

Salah satu hal penting juga dalam paradigm pembangunan yang berkaitan dengan peran serta masyarakat adalah pemberdayaan. Pemberdayaan secara sederhana dapat dimaknai sebagai upaya memampukan masyarakat agar mempunyai posisi tawar yang strategis terhadap segala macam program pemerintah agar masyarakat dapat menikmati hasil atau efek dari berbagai macam program itu demi kelangsungan kehidupannya yang lebih baik.

Sebagai mana diungkapkan oleh Mardikanto (2010) istilah "pemberdayaan masyarakat” sebagai terjemahan dari kata "empowerment” mulai ramai digunakan dalam bahasa sehari-hari di Indonesia bersama-sama dengan istilah "pengentasan kemiskinan” (poverty allevation) sejak digulirkannya Program Inpres no. 5/1993 yang kemudian lebih dikenal sebagai Inpres IDT (Inpres Desa Tertinggal). Sejak itu, istilah pemberdayaan dan pengentasan kemiskinan merupakan "saudara kembar” yang selalu menjadi topic dan kata kunci dari upaya pembangunan.

Maka kemudian pengertian pemberdayaan sendiri menjadi perhatian banyak pihak dari berbagai bidang, disiplin ilmu dan berbagai pendekatan. Menurut Rappaport dalam Suharto (1998); “pemberdayaan menunjuk pada usaha realokasi sumber daya melalui pengubahan struktur sosial. Pemberdayaan adalah suatu cara yang diarahkan kepada masyarakat, organisasi atau komunitas agar mampu menguasai (berkuasa atas) kehidupannya”. Kemudian Torre mengemukakan bahwa pemberdayaan adalah:

"A process through which people become strong enough to participate within, share in the control of, and influence events and institutions affecting their lives, (and that in part) empowerment necessitates that people gain particular skills, knowledge and sufficient power to influence their lives and the live those they care about".

Jadi tujuan pemberdayaan pada hakekatnya seperti yang dijelaskan Ife (2008): "Empowerment aims to increase the power of disadvantage".

Kemudian oleh Parson (1994) menjelaskan tentang dimensi pemberdayaan yang terdiri dari 3 dimensi yaitu:

1. A development process that begins with individual growth, and possibly culminates in larger scope such as sosial change. 
2. A psychological state marked by heightened feelings of self-esteem, efficacy and control.

3. Liberation resulting from a sosial movement, which begins with education and politization of powerless people and later involves collective attempts by the powerless to gain power and to change those structure that remain oppressive.

Kemudian pada bagian lain menurut beberapa penulis, seperti Solomon (1976), Rappaport (1981, 1984), Pinderhughes (1983), Swift (1984), Weick, Rapp, Sulivan \& Kristhardt (1989) didapatkan kesamaan prinsipil dalam pemahaman tentang pemberdayaan yaitu:

1. Empowerment is a collaborative process, with the people and the practitioner working together as a partner.

2. The empowering process views society systems as competent and capable, given access to resources and opportunities.

3. Competence is acquired or refined through life experience, particularly experience affirming efficacy, rather than from circumstances where one is told what to do.

4. Society must perceive them selves as casual agent, able to effect changes.

5. Solution, evolving from the particular situation, are necessarily diverse and emphasize 'complexities of multiple contributory factors in any problem situation (Solomon, 1976:27)

6. Informal sosial networks are a significant sources of support for mediating stress and increasing one ss competence and sense of control.

7. People must participate in their own empowerment; goals, means, and outcomes must be self defined.

8. Level of awareness is a key issue in empowerment; knowledge mobilizes action for change (Swift \& Levin, 1987:81)

9. Empowerment involves access to resources and the capacity to use those resources in an effective way.

10. The empowerment process is dynamic, synergistic, ever changing, and evolutionary; problems always have multiple solution.

11. Empowerment is achieve through the parallel structure of personal and socioeconomic development”. (Du Bois \& Miley, 1992)

Menurut Ife (2008), pemberdayaan memuat dua pengertian kunci yakni kekuasaan dan kelompok lemah. Kekuasaan di sini diartikan bukan hanya menyangkut kekuatan politik namun mempunyai arti luas yang merupakan penguasaan masyarakat atas:

1. Power over personal choices and life chances. Kekuasaan atas pilihanpilhan personal dan kesempatan-kesempatan hidup, kemampuan dalam membuat keputusan-keputusan mengenai pilihan hidup, tempat tinggal dan pekerjaan dan sebagainya.

2. Power over the definition of need. Kekuasaan atas pendefinisian kebutuhan, kemampuan menentukan kebutuhan selaras dengan aspirasi dan keinginan. 
3. Power over ideas. Kekuasaan atas ide atau gagasan, kemampuan mengekspersikan dan menyumbang gagasan dalam interaksi, forum dan diskusi secara bebas dan tanpatekanan.

4. Power over institutions. Kekuasaan atas lembaga-lembaga, kemampuan menjangkau, menggunakan dan mempengaruhi lembaga-lembaga masyarakat seperti; lembaga pendidikan, kesehatan, keuangan serta lembaga-lembaga pemenuh kebutuhan hidup lainnya.

5. Power over resources. Kekuasaan atas sumber daya, kemampuan memobilisasi sumber daya formal dan informal serta kemasyarakatan dalam memenuhi kebutuhan hidup.

6. Power over economic activity. Kekuasaan atas aktivitas ekonomi kemampuan memamfaatkan dan mengelola mekanisme produksi, distribusi serta pertukaran barang dan jasa.

7. Power over reproduction. Kekuasaan atas reproduksi, kemampuan dalam kaitannya dengan proses reproduksi dalam arti luas seperti pendidikan, sosialisasi, nilai dan prilaku bahkan kelahiran dan perawatan anak.

Pemberdayaan tidak serta merta langsung begitu saja tercipta namun sebuah proses yang harus dilalui oleh masyarakat yang dianggap tidak berdaya berhadapan dengan pemerintah yang berkuasa. Maka dalam bagian ini pemberdayaan merupakan sebuah proses agar setiap orang menjadi cukup kuat untuk berpartisipasi dalam, berbagai pengontrolan atas (pemerintah), dan mempengaruhi, kejadiankejadian serta lembaga-lembaga yang mempengaruhi kehidupannya.. pemberdayaan menekankan bahwa orang memperoleh keterampilan,pengetahuan, dan kekuasaan yang cukup untuk mempengaruhi kehidupannya dan kehidupan orang lain yang menjadi perhatiannya. (Parsons,1994)

Berkaitan dengan hal diatas maka perlu lah difahami bahwa kekuasaan yang misalnya milik pemeritah yang berhadapan dengan masyarakat yang tidak berdaya haruslah difahami sebagai kekuasaan yang tidak vakum atau terisolasi hanya pada satu pihak saja. Kekuasaan akan senantiasa hadir dalam relasi antar manusia karena itu antara kekuasaan dan hubungan kekuasaan dapat berubah. Dengan pemahaman seperti ini jika dikaitkan dengan pemberdayaan maka pemberdayaan sebagai sebuah proses perubahan memiliki konsep yang bermakna, menurut Mardikanto (2010) proses pemberdayaan tergantung akan dua hal, yaitu :

(1) Bahwa kekuasaan dapat berubah. Jika kekuasaan tidak dapat berubah, pemberdayaan tidak mungkin terjadi dengan cara apapun.

(2) Bahwa kekuasaan dapat diperluas. Konsep ini menekankan pada pengertian kekuasaan yang tidak statis, melainkan dinamis.

Pendapat diatas diperkuat oleh Sumodiningrat (1999) bahwa sebagai suatu proses tentu pemberdayaan mempunyai hakikat yang berpusat pada manusia dan kemanusiaan, dengan kata lain manusia dan kemanusiaan sebagai tolak ukur normative, structural, dan substansial. Selain itu pemberdayaan sebagai proses mempunyai tujuan untuk memampukan dan memandirikan masyarakat, sehingga adanya peningkatan harkat dan martabat masyarakat yang terbebas dari belenggu kemiskinan dan keterbelakangan. 
Berkaitan dengan hal itu Mardikanto (2010) melihat pemberdayaan dapat dilihat dari tiga sisi, yaitu :

Pertama, menciptakan suasana atau iklim yang memungkinkan potensi masyarakat berkembang (enabling). Disini bermakna bahwa manusia atau masyarakat memiliki potensi yang dapat dikembangkan.

Kedua, memperkuat potensi atau daya yang dimiliki masyarakat (empowering). Hal ini menyangkut membukanya masukan (input) serta pembukaan berbagai peluang (opportunities) yang akan membuat masyarakat menjadi lebih berdaya. Hal ini bisa dilakukan dengan peningkatan taraf pendidikan, dan derajat kesehatan, serta akses ke dalam sumber-sumber kemajuan ekonomi seperti modal, teknologi, informasi, lapangan kerja, dan pasar. Ditambah lagi ditunjang dengan sarana dan prasarana fisik seperti irigasi, jalan, listrik, kemudian dari segi sosial misalnya sekolah dan fasilitas pelayanan kesehatan yang terjangkau oleh masyarakat lapisan bawah. Ditambah lagi dengan ketersediaan lembaga - lembaga pendanaan, pelatihan, dan pemasaran terutama di pedesaan. Selain itu juga yang tidak kalah penting adalah penguatan nilai-nilai etos kerja yang professional seperti kerja keras, hemat, keterbukaan, dan sikap bertanggungjawab. Ketiga, memberdayakan mengandung arti melindungi. Dalam proses pemberdayaan harus dicegah yang lemah menjadi bertambah lemah, oleh karena kekurangberdayaan dalam menghadapi yang kuat. Melindungi harus dilihat sebagai upaya untuk mencegah terjadinya persaingan yang tidak seimbang, serta eksploitasi yang kuat atas yang lemah. Pemberdayaan masyarakat bukan membuat masyarakat menjadi makin tergantung pada berbagai program pemberian (charity). Maka konsep pemberdayaan adalah masyarakat tidak dijadikan objek dari berbagai proyek pembangunan, tetapi sebagai subjek dari upaya pembangunannya sendiri.

Pemahaman tentang proses pemberdayaan ini akan kembali berfokus pada masyarakat yang secara otonom ikut serta dalam pengambilan keputusan dari suatu kelompok masyarakat yang dilandasi dengan penerapan aspek demokratis, partisipasinya yang berfokus pada lokalitas, dengan pertimbangan bahwa masyarakat akan merasa siap diberdayakan melalui isu-isu lokal. Kemudian ditambakan pula oleh Subejo yang mengartikan proses pemberdayaan masyarakat merupakan upaya yang disengaja untuk memfasilitasi masyarakat local dalam merencanakan, memutuskan, dan mengelola sumber daya lokal yang dimiliki melalui collective action and networking sehingga pada akhirnya mereka memiliki kemampuan dan kemandirian secara ekonomi, ekologi, dan sosial.

\section{Kesimpulan}

1. Dalam proses pembangunan yang dilakukan suatu bangsa harus memperhatikan seluruh rakyat, tanpa kecuali masyarakat yang masuk dalam kategori miskin.

2. Program kesehatan bagi masyarakat miskin merupakan tanggungjawab bersama antara pemerintah dan rakyat, agar cita-cita bangsa bisa tercapai dengan baik dan maksimal.

3. Pemberdayaan masyarakat merupakan langkah awal bagi kemandirian masyarakat untuk bisa lebih berperan aktif dalam pembangunan. 


\section{Daftar Pustaka}

Badan Kependudukan dan Keluarga Berencana Nasional. 2013. Buku Profil Pengendalian Kuantitas Penduduk Jawa Timur. Surabaya.

Chambers, R. 1987, 'Sustainable livelihoods, environment and development: putting poor rural people first', IDS Discussion Paper 240, Brighton: Institute of Development Studies.UK.

Donabedian, A. 1980. Aspect of Medical Care Administration. Harvard University Press. USA.

Du Bois, Brenda dan Karla Krogsrud Miley. 1992. Social Work: An Empowering Profession, (Boston: Allyn and Bacon).

Friedman, John. 1992. Empowerment: The Politics of Alternative Development. Cambridge: Blackwell.UK.

Ife, Jim \& Tesoriero, Frank, 2008.Community Development: Alternatif Pengembangan Masyarakat Diera Globalisasi. Pustaka Pelajar. Yogyakarta.

Kartasasmita, Ginanjar . 1996. Pemberdayaan Masyarakat: Konsep Pembangunan yang berakar pada Masyarakat. Bappenas . Jakarta.

Mardikanto, Totok. 2010. Konsep-konsep Pemberdayaan Masyarakat. Fakultas Pertanian UNS-UPT Penerbitan dan Pencetakan UNS (UNS Press). Surakarta.

Miles,MB \& Huberman, AM. 1994. An Expanded Sourcebook : Qualitative Data Analysis ( $2^{\text {nd }} e d$.) Thousand Oaks. Sage Publication.CA.

Payne, Malcolm. 1997. Modern Social Work Theory. Basingstoke, MacMillan. Hampshire (UK).

Potter, P.A, Perry, A.G. 2005. Buku Ajar Fundamental Keperawatan : Konsep, Proses, dan Praktik.Edisi 4.Volume 2.Alih Bahasa : Renata Komalasari,dkk.Jakarta:EGC.

Ritzer, George\& Goodman, Douglas, J. Teori Sosiologi Modern Edisi Keenam, terj., dari Judul Asli Modern Sociological Theory $6^{\text {th }}$ Edition. Oleh Alimandan. Prenada Media. Jakarta.

Ruth, J.Parsons. 1994. Empowerment-Oriented Social Work Practice With the Elderly. Published by Brooks/Cole Pub Co.USA.

Suharto, Edi. 2009. Membangun Masyarakat Memberdayakan Masyaraka. PT Refika Aditama. Bandung.

Sumodiningrat, Gunawan. 1999. Pemberdayaan Masyarakat dan Jaring Pengaman Sosial.Gramedia Pustaka Utama. Jakarta. 
Suparlan, Parsudi. 1993. Kemiskinan di Perkotaan. Yayasan Obor, Indonesia.

Supriatna, T. 1997. Birokrasi Pemberdayaan dan Pengentasan Kemiskinan. Humaniora Utama Press. Bandung.

Usman, Sunyoto. 1998. Pembangunan dan Pemberdayaan Masyarakat. Pustaka Pelajar. Yogyakarta.

Tjokrowinoto,Moeljarto.2004. Pembangunan Dilema Dan Tantangan. Pustaka Pelajar. Yogyakarta.

Warsono, dkk. 2011. Kajian Kebijakan Sosial (Kajian Tentang Kebijakan Pendidikan (BOS), Kesehatan (JAMKESMAS), dan Perlindungan Anak di Jawa Tengah dan Jawa Timur. UNICEF. Semarang.

\section{Kumpulan Peraturan:}

Peraturan Menteri Kesehatan Republik Indonesia Nomor 28 Tahun 2014 Tentang Pedoman Pelaksanaan Program Jaminan Kesehatan Nasional.

Peraturan Menteri Kesehatan Republik Indonesia Nomor 71 Tahun 2013 Tentang Pelayanan Kesehatan Pada Jaminan Kesehatan Nasional.

Keputusan Menteri Kesehatan Nomor 1259/Menkes/SK/XII/2009 tentang Petunjuk Teknis Pelayanan Jamkesmas Bagi Masyarakat Miskin Akibat Bencana, Masyarakat Miskin Penghuni Panti Sosial, dan Masyarakat Miskin Penghuni Lembaga Pemasyarakatan serta Rumah Tahanan Negara.

Undang - Undang Republik Indonesia Nomor 24 Tahun 2011 Tentang Badan Penyelenggara Jaminan Sosial.

Undang-Undang Republik Indonesia Nomor 36 Tahun 2009 Tentang Kesehatan.

Website:

Pemberdayaan\%20Masyarakat\%20Miskin\%20di\%20Pedesaan.html http://arali2008.wordpress.com/2010/12/24/indeks-pembangunan-kesehatanmasyarakat

www.bps.jatim.go.id

www.depkes.go.id/index.php?vw=2\&id=1337

www. dr-suparyanto.blogspot.com

https://profsyamsiah.wordpress.com/2009/04/23/49/

http://www.vistapulsa.com/wuih-449-860-orang-surabaya-miskin.html

www.waspada.co.id

www.wikipedia.co.id

Media Cetak :

Harian SURYA, Sabtu,17 Januari 2015 


\section{Hasil Penelitian:}

Muhith, Abdul. 2012. Pengembangan Model Mutu Asuhan Keperawatan Berdasarkan Analisis Kinerja Perawat dan Kepuasan Perawat serta Pasien di Rumah Sakit Kabupaten Gresik. Disertasi Universitas Airlangga. Surabaya.

Yuwono, Slamet Riyadi. 2008. Penggunaan Interpersonal Skill dalm Problem Solving Cycles sebagai Upaya Peningkatan Efektifitas Tim (Penerapan Riset Operasional Manajemen RSUD Dr. Soetomo Surabaya). Disertasi Universitas Airlangga. Surabaya. 